\title{
A level playing field?
}

\section{Drug testing in sport aims to promote fair play, but the science behind the tests needs to be more open.}

$T$ he opening ceremony of the 2008 Olympic Games in Beijing has yet to take place, but already several athletes face charges of taking substances banned by the International Olympic Committee. These are just the latest in a long line of cases in which competitors have been accused of using performance-enhancing substances. Far from quelling such practices, the advent of drug testing in sport in the late 1960 s stimulated an arms race between regulators and the cheats.

Today, some athletes and their coaches continue to risk their reputation, and sometimes the athletes' long-term health, for the chance to dope undetected. In the process, they push the human body to its limits and go beyond what is known about the drugs being taken. The latest drugs are designed with testing in mind, so that they either clear from the body quickly or do not produce the tell-tale metabolite spikes in blood and urine samples. As a result, the testing labs must also push to stay one step ahead of the cheats.

On page 692, biostatistician Donald Berry of the University of Texas in Houston outlines what he sees as problems with the way doping tests are conducted. He argues that anti-doping authorities have not adequately defined and publicized how they arrived at the criteria used to determine whether or not a test result is positive. The ability of an anti-doping test to detect a banned substance in an athlete is calibrated in part by testing a small number of volunteers taking the substance in question. But Berry says that individual labs need to verify these detection limits in larger groups that include known dopers and non-dopers under blinded conditions that mimic what happens during competition.

Nature believes that accepting 'legal limits' of specific metabolites without such rigorous verification goes against the foundational standards of modern science, and results in an arbitrary test for which the rate of false positives and "Drug testing should not be exempt from the scientific principles and standards that apply to other biomedical sciences." false negatives can never be known. By leaving these rates unknown, and by not publishing and opening to broader scientific scrutiny the methods by which testing labs engage in study, it is Nature's view that the anti-doping authorities have fostered a sporting culture of suspicion, secrecy and fear.

Detecting cheats is meant to promote fairness, but drug testing should not be exempt from the scientific principles and standards that apply to other biomedical sciences, such as disease diagnostics. The alternative could see the innocent being punished while the guilty escape on the grounds of reasonable doubt.

\section{Clean hands, please}

\section{The Italian government needs to maintain a careful distance from industry.}

ifteen years ago, at the height of Italy's 'Clean Hands' anticorruption campaign, police broke into the house of Duilio Poggiolini, head of the national committee for drug registration, and discovered gold bullion under his floorboards. For many Italians, the image of that gleaming bullion still resonates - an enduring symbol of a time when government officials, up to and including the health minister, routinely took bribes from the pharmaceutical industry to approve drugs and fix their prices.

Steps were taken to avoid such a situation arising again. So it is worrying that Nello Martini, a pharmacist with no political associations, has been removed by Prime Minister Silvio Berlusconi's new government as head of AIFA, the autonomous agency created in 2004 to register drugs and supervise their use. Martini successfully carried out a mandate to limit spiralling drug expenditure to $13 \%$ of the total health budget. But in the process he incurred the wrath of industry. Only a few weeks ago, government prosecutors in Turin charged Martini with disastro colposo, or 'causing unintentional disaster', for bureaucratic delays in updating the packaging information on the side effects of a few drugs - although none required more than minor rewording of existing text.

Martini was replaced in the middle of July by microbiologist Guido Rasi, a member of AIFA's administrative board, who has been described in the Italian press as being close to the far-right party Alleanza Nazionale, which forms part of Berlusconi's coalition government. Even more worryingly, the government, which took office in May, says it plans to reduce AIFA's power by separating the pricing of drugs from technical considerations of their efficacy, bringing pricing back into the health and welfare ministry.

At a time when all countries are struggling to find a way to pay for hugely expensive new-generation drugs within limited budgets, this makes little sense. The autonomous agency needs to be able to integrate all technical and economic information if Italy is to operate a cost-effective health system. Moreover, the health and welfare ministry's connections with industry are uncomfortably close. For example, the wife of the minister Maurizio Sacconi is the directorgeneral of Farmindustria, the association that promotes the interests of the pharmaceutical industry.

In fact, Berlusconi's government has shown unsettling tendencies to allow industrial interests to gain influence over state agencies. A few weeks after Martini's dismissal, the Italian space agency was put into the hands of a commissioner who heads the space division of the aerospace giant Finmeccanica. The government should think twice about whether it really wants to open the door that was deliberately closed after the Poggiolini affair. 